Article

\title{
Integrated Economic and Financial Analysis of China's Sponge City Program for Water-resilient Urban Development
}

\author{
Xiao Liang \\ College of Economics, Shenzhen University, Shenzhen 518060, China; liangx@szu.edu.cn; Tel.: +86-755-26733256; \\ Fax: +86-755-6567150
}

Received: 25 January 2018; Accepted: 26 February 2018; Published: 1 March 2018

\begin{abstract}
To improve Chinese cities' resilience to climate change, the Sponge City Program, which was designed to tackle water pollution, storm water management, and flooding, was initiated in 2014. Being a major policy initiative, the Sponge City Program raises heated discussions among Chinese academics; however, no relevant extensive economic or financial analysis has been conducted. The research carries out an integrated economic and financial analysis on the Sponge City Program from the perspectives of two stakeholders: the government and the project manager. Different stakeholders have unique perspectives on the management of water projects. This study has two parts: economic analysis and financial analysis. The economic analysis is from the government perspective, and considers all the economic, environmental, and social effects. The financial analysis is from the project manager's perspective, and judges the financial feasibility of projects. Changde city, one of the demo cities of Sponge City Program, is chosen for the research. The results show that from the perspective of the government, the Sponge City Program should be promoted, because most water projects are economically feasible. From the perspective of the project manager, the program should not be invested in, because the water projects are financially infeasible. A more comprehensive and integrated plan for developing and managing the water projects of the Sponge City Program is required. Otherwise, the private sector may not be interested in investing in the water projects, and the water projects may not be operational in the long term.
\end{abstract}

Keywords: China; economic analysis; financial analysis; Sponge City Program; urban water management

\section{Introduction}

Because of climate change, the frequency of heavy rainfall events has increased in China in recent years. For example, one-quarter of Chinese areas experienced approximately 30 heavy rainfall incidents in 2016, resulting in severe city flooding in approximately 200 cities [1,2]. Moreover, rapid urbanization increases the use of steel, cement, and concrete in cities, severely hampering city-water filtration and flow. Consequently, urban channels and rivers are highly polluted and city flooding is worsened. The water system of Chinese cities is increasingly fragile and deteriorating.

To improve water resilience in Chinese cities, the Sponge City Program was initiated in 2014. A total of 16 cities were selected to be demo cities for the program in 2015; and, 14 cities, including Beijing, Tianjin, Shanghai, and Shenzhen, were added in 2016. The demo cities are distributed throughout China and have varying annual rainfall. The number of demo cities is expected to increase [3].

As a large and influential program, the Sponge City Program raises heated discussions among Chinese academics. Specialists in urban planning argue that the program helps to improve the urban water environment and decreases the amount of concrete in a city $[3,4]$. Researchers in urban 
management argue that the demo cities have not yet achieved the coordination and cooperation among different city departments that is necessary for successful implementation of the Sponge City Program $[5,6]$. Moreover, some researchers worry that the program faces considerable challenges. While various water treatment projects can be constructed, it is difficult to alter the entire urban water environment $[6,7]$.

In literature, there is less discussion on the economic or financial analysis of the Sponge City Program. Although some studies have identified potential financial problems, such as a lack of financial sources, which these projects can face $[5,8,9]$, there remains a notable dearth of discussion about the Sponge City Program from an economic perspective. Concurrent implementation of numerous water projects in China prevents them from operating as desired, because economic, environmental, and social factors may hamper the continuous operation of the project [10]. An integrated economic and financial analysis is essential to clarify the efficiency and feasibility of the Sponge City Program [11].

The cost of implementing the Sponge City Program is substantial, estimated to be US\$15-22 million for each square kilometer [12]. Currently, the central government is committed to providing financial assistance for only three years, and the private sector is expected to be the primary financial source thereafter. For example, in Wuhan, which is one of the demo cities, private investors are expected to fund $50 \%$ of the total investment in water projects; local governments would contribute $40 \%$, and the central government would contribute $10 \%$. In literature, private sector is regarded to be playing an important role in water project management $[13,14]$. Private investors, however, have no quantitative information about economic, environmental, and social value of the Sponge City Program. Financial analysis of private-sector investment is needed but is currently lacking [9]. Whether private investors are interested in investing in the Sponge City Program remains unclear.

The paper analyzes the economic and financial feasibility of the Sponge City Program from the perspectives of two stakeholders: the government and the project manager. Different stakeholders have unique perspectives on water project management. This analysis has two parts, economic and financial. The economic analysis considers the government perspective and determines all possible economic, environmental, and social effects of the water projects. The financial analysis considers the project manager's perspective and judges the financial feasibility of the project. Changde city is chosen for the present case study because it has more complete data on water projects than the other demo cities. Water projects in Changde city are already operational, whereas projects in other demo cities mostly remain in construction or planning. A comprehensive economic and financial analysis of the Sponge City Program can be performed through an intensive case study of Changde city.

The detail of water projects of the Sponge City Program of Changde city is introduced in Section 2. Section 3 describes the evaluation framework of the research, which includes two parts of analysis: economic analysis and financial analysis. The economic analysis of each economic, environmental and social effect is discussed and the results are shown in Section 4. The financial analysis and the results are presented in Section 5. Conclusions are drawn in Section 6. All data in this study are sourced from interviews with project managers, city government officials, and other relevant institutes.

\section{The Projects in Changde City}

Changde is located in northern Hunan province, and was an important political, economic, and cultural center during the Ming dynasty because of its rich water systems and convenient transportation. The GDP of Changde in 2017 is around CNY $¥ 300$ billion. Today, however, the city is congested with polluted and smelly rivers, channels, and lakes [15,16]. Parts of some of Changde's channels are completely blocked by solid waste. Moreover, Changde frequently suffers from serious flooding events, which occur approximately one times per four years. In 1998, one particularly severe flooding event in Changde resulted in economic losses of approximately CNY $¥ 0.1$ billion [17].

To solve the water problems, eight water projects were constructed along the city's main river the Chuanzi River, which branches off the Yangzi River. All eight projects, as shown in Figure 1, are part of the Sponge City Program, and were developed to decrease the frequency of flooding in 
Changde, improve the water quality of the Chuanzi River, and restore the Chuanzi River to its natural appearance. Figure 1 illustrates the locations of the eight water projects (the shaded areas indicate the path of the Chuanzi River). The capacities of eight projects are shown in Table 1. All of the projects have completed construction and been operational by a state-owned enterprise.

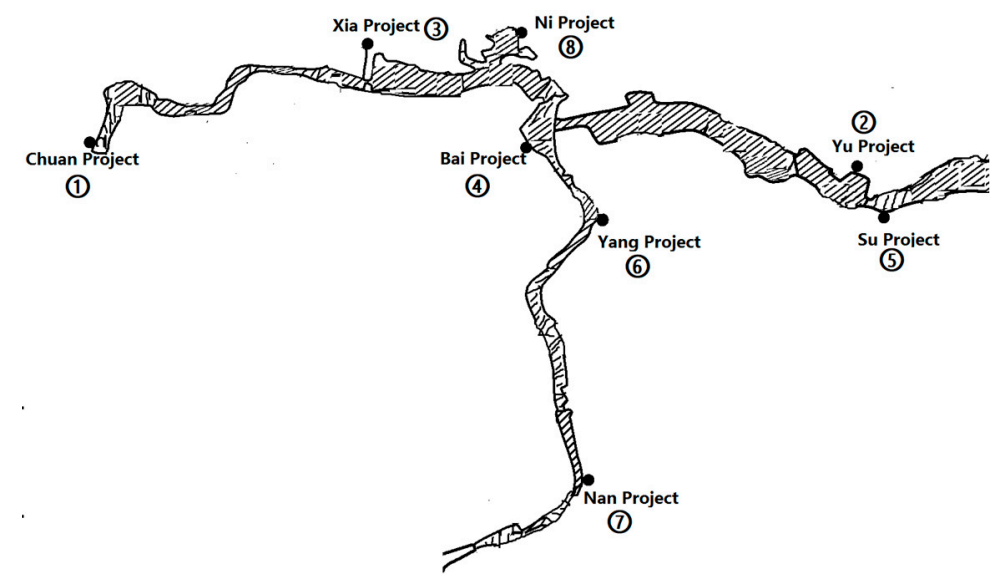

Figure 1. Distribution of the eight water projects in Changde City.

Table 1. Capacities of Changde's water projects.

\begin{tabular}{ccc}
\hline & Project & Capacity $\mathbf{( m}^{\mathbf{3}} \mathbf{)}$ \\
\hline 1 & Chuan project & 30,000 \\
2 & Yu project & 15,000 \\
3 & Xia project & 30,000 \\
4 & Bai project & 36,000 \\
5 & Su project & 30,000 \\
6 & Yang project & 15,000 \\
7 & Nan project & 7,500 \\
8 & Ni project & 10,000 \\
\hline
\end{tabular}

Currently, all eight projects just completed the construction with an identical design, functioning, and financial sources. Each project consists of rainwater harvesting plants and an ecological purification area, as shown in Figure 2. The ecological purification area is made up of different types of plants, including phytoplankton and reeds. During the rainy season, rainwater harvesting plants can store abundant amounts of rainwater, which helps to mitigate potential flooding. The rainwater is also purified by both the rainwater harvesting plants and the ecological purification area before entering the river; this step prevents pollutants from freely flowing into the river. During the dry season, the river water can be purified naturally because the ecological purification area is directly linked to the river. The ecological purification area also functions as a water reserve, and is a wetland park for nearby residents. The total area of a project is around $4 \mathrm{~km}^{2}$.

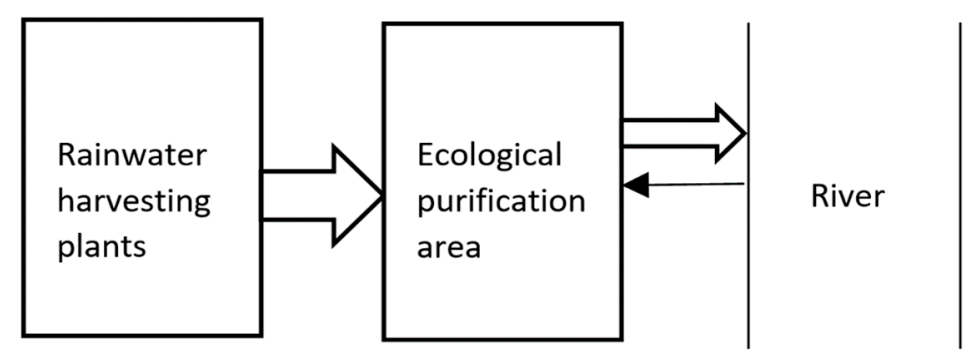

Figure 2. Structure of the water project. 


\section{Evaluation Framework}

Figure 3 shows the evaluation framework of this research. The government and the project manager, two pivotal stakeholders in the management of the water project, may have different perspectives on water project management [18]. From government perspective, the emphasis is the contribution of water projects to the society; from the perspective of project managers, the concern is the financial performance of the investment. This research analyzes from the perspectives of two stakeholders separately to obtain a more comprehensive conclusion. The economic and financial feasibility of water projects are evaluated a through cost-benefit analysis. If the benefit is larger than cost, then the project is regarded as economically or financially feasible; otherwise, the project is considered infeasible.

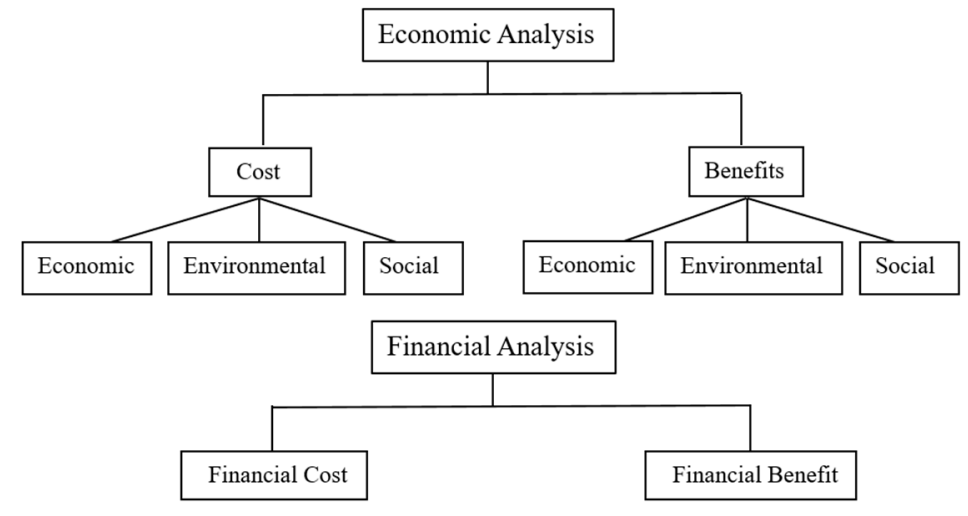

Figure 3. Evaluation framework.

In the economic analysis, all economic, environmental, and social costs and benefits that are associated with the projects are given a monetary value. The monetary value of each effect is principally obtained through indirect methods, because it is too complex to calculate the environmental and social values. Transfer payments, such as subsidies, are not considered in the economic analysis because they do not consume or create any new value for society. In the financial analysis, financial benefit is defined as the profit that the project manager can earn from the projects, and financial cost is the total spending to build and operate the projects.

\section{Economic Analysis}

A list of all the possible economic, social, and environmental impacts that are associated with the projects is presented in Table 2. Notably, the project does not have any environmental cost because it operates naturally and automatically without consuming energy, and does not cause any social cost. Thus, in Table 2, environmental cost and social cost are represented by an " $N$ " to denote "no effect." The detail of explanation and values determination is presented at the following sections. 
Table 2. Economic, social, and environmental effects of projects.

\begin{tabular}{ll}
\hline Items & All Possible Effects \\
\hline \multirow{2}{*}{ Economic Cost } & Initial investment \\
Environmental cost & O\&M cost \\
Social Cost & $N$ \\
Economic Benefits & Increase of jobs \\
Environmental benefits & Tourism \\
Social benefits & Decrease of economic loss due to flooding \\
& Incrovement on river water quality \\
& Note: "N" means no effects.
\end{tabular}

\subsection{Economic Cost}

From a societal perspective, the construction, operation, and maintenance of the water project are regarded as the consumption of resources, so initial investment and operation and maintenance (O\&M) cost are included in the economic cost evaluation. Because there are not many trade items in the initial investment and O\&M cost, it can be assumed that market prices did not largely distort the values; hence, market prices were directly used as the economic values of the project. For example, the total initial investment in the Chuan project was approximately CNY $¥ 0.13$ billion, of which, $60 \%$ was used for water stretch reconstruction and $40 \%$ was used to construct the rainwater harvesting plants, ecological purification area, and leisure area. The O\&M cost were solely related to management personnel salaries because no machines or chemicals are required to operate the project. For example, in the Chuan project, a total of 30 workers are involved in managing the project, with 20 workers in charge of cleaning and maintaining the ecological purification area and leisure park and 10 workers in charge of rainwater harvesting maintenance. The average salary of a worker is nearly CNY $¥ 4,000$ per month. The economic costs (defined as $C_{E}$ ) of the project were determined by using Equation (1):

$$
C_{E}=I+\sum_{t=1}^{n} \frac{a \times M}{(1+r)^{t}}
$$

where $I$ is the initial investment, $a$ is the average salary of the workers, $M$ is the number of workers, $r$ is the discount rate, and $n$ is the evaluation period. According to the "Chinese Economic Evaluation Parameters on Construction", a publication released by the National Development Reform and Commission, the nominal discount rate used for cost benefit studies in China is $8 \%$. This rate is determined by socioeconomic growth, the expected inflation rate, and the opportunity cost of capital. The estimated period $(n)$ is 10 years which is used in most of literature.

\subsection{Economic Benefit}

The projects lead to the economic benefits of increasing jobs and tourism industry in the Chuanzi River. Firstly, job positions were created because of the projects, which improved employment in the region. In order to estimate the monetary value of improved employment, an indirect valuation method is employed. Employment elasticity, which is the ratio of employment growth to economic growth, was adopted in the present study. Scholars have determined that if the employment elasticity is 0.1 , then an economic growth of $1 \%$ increases employment by $0.1 \%[19,20]$. We assume that the amount of $1 \%$ of economic growth is regarded as the social benefit value due to $0.1 \%$ of employment growth. The employment elasticity of China overall is estimated to be 0.3 [20], and because of limited data, 
it was assumed that the employment elasticity of China is applicable to Changde city. The economic benefit of increasing the number of jobs in Changde city was determined by using Equation (2):

$$
B_{O 1}=\frac{\frac{w}{W}}{\beta} \times Y
$$

where $B_{O 1}$ is the economic benefit of increasing jobs, $\beta$ is the employment elasticity, $w$ is the number of new jobs that are created due to the implementation of a project, $W$ is the total number of people employed in Changde city, and $Y$ is the GDP of Changde city.

Secondly, the industry of tourism of the Chuanzi River develops gradually since the Chuanzi River becomes clean. This could be regarded as the economic benefits that are caused by the projects. Presently, cruise activity is the main tourism project in the Chuanzi River. The number of visitors is around 70 thousands persons each day (defined as $U$ ), and the average spending of each visitor is around CNY $¥ 200$ per day (defined as $u$ ). It is supposed that each project does a same contribution to the cruise tourism. Accordingly, the economic benefit of tourism of a project (defined as $B_{O 2}$ ) could be determined by Equation (3):

$$
B_{O 2}=\sum_{t=1}^{n} \frac{u \times U}{(1+r)^{t}} / 8
$$

\subsection{Environmental Benefit}

In recent years, city flooding caused substantial economic loss in Changde. Eight water projects can effectively release the stress of flooding, and thus prevent economic loss at certain level. The absence of economic loss from city flooding can be regarded as an economic benefit of the projects. It is too complicated to evaluate economic losses from flooding in Changde directly because there are few existing studies on Changde. However, relevant studies conducted elsewhere in China illustrate that flooding-associated economic loss is determined by a city's economic development level and social situation [21-25]. Wuhan is close to Changde and is located right next to the Yangzi River, and thus suffers from frequent floods; additionally, the social development and culture of both cities are similar. Therefore, an indirect method was used to convert the average gross domestic product (GDP) between Changde and Wuhan, and estimate economic loss due to flooding in Changde. Shi et al. (2013) analyzes economic loss that is caused by a flooding event in Wuhan, calculating economic losses at approximately CNY $¥ 0.7$ billion in 2012 [25]. According to the 2013 statistical yearbooks of Wuhan and Changde, the average GDP per area of Wuhan is CNY $¥ 0.106 / \mathrm{km}^{2}$ and that of Changde is CNY $¥ 0.0124 / \mathrm{km}^{2}$. This indicates that Wuhan’s economic development is 8.5 times higher than that of Changde. Therefore, the economic loss due to city flooding in Changde was estimated to be approximately CNY $¥ 80$ million in 2012. As the serious flooding in Changde occurs approximately one time per four years [17], the average economic loss borne by Changde due to flooding is approximately CNY $¥ 20$ million in each year (defined as $G$ ).

The amount by which economic loss was reduced due to a water project (defined as $B_{E 1}$ ) could be determined by the economic loss of Changde $(G)$ and the probability of economic loss within the project area (defined as $g$ ), as shown in Equation (4). The residents in the area of eight projects were most likely to face economic loss from a flooding event because they live right next to the river. Thus, the probability of economic loss within the Chuan project area $(g)$ can be determined by the ratio of the population in a project to the total population of Changde.

$$
B_{E 1}=\sum_{t=1}^{n} \frac{G \times g}{(1+r)^{t}}
$$

Secondly, the projects effectively diminish water pollution in the Chuanzi River, thereby improving the quality of the water environment. This is a key environmental benefit of the projects. The water pollution in Changde mainly comes from the Chuanzi River (a branch off of the Yangzi River), which is 
the only water net in the Changde city center. The reduced economic loss on water pollution due to the Chuan project (defined as $B_{E 2}$ ) can be calculated by multiplying total economic loss due to water pollution in Chuanzi River (defined as $O$ ) by the ratio of the pollution of each project to the pollution of Chuanzi River.

Human health loss is the main loss caused by water pollution in the project area, because the project is located in the city center without industry and agriculture. It means that the project reducing water pollution leads to a benefit of human health improvement. The loss of human health accounts for $23 \%$ of total economic loss from water pollution (defined as $p_{1}$ ), and the contribution of each project on improving water quality of the Chuanzi River (defined as $p_{2}$ ) [16]. Hence, the ratio of a project to the Chuanzi River can be obtained by multiplying $p_{1}$ by $p_{2}$.

The economic loss due to water pollution in Chuanzi River $(O)$ can be determined through GDP conversion. Li et al. (2003) extensively evaluated the economic loss caused by water pollution in China, which includes loss that is related to industry, agriculture, municipal facilities, and human health [24]. These researchers estimated that the total economic loss accounted for $1.6 \%, 1.2 \%$, and $5 \%$ of the GDP in the areas that are upstream of the Yangzi River, along the middle of the Yangzi River, and downstream of the Yangzi River [26]. As Changde is located near the middle area along the Yangzi River, we can assume that the economic loss due to water pollution is $1.2 \%$ of the GDP in Changde. The GDP of Chuanzi River area was CNY $¥ 85.5$ billion in 2013, so the total amount of economic loss that is caused by water pollution from the Chuanzi River can be calculated to be approximately CNY $¥ 1.026$ billion $(O)$. Therefore, the environmental benefit of a project can be calculated, as follows:

$$
B_{E 2}=\sum_{t=1}^{n} \frac{O \times p_{1} \times p_{2}}{(1+r)^{t}}
$$

\subsection{Social Benefits}

Within each project area, there is a nearly $0.15 \mathrm{~km}^{2}$ wetland park. Before the park was constructed, people rarely walked around the area because of the bad smell emanating from the polluted river bank; currently, nearly 5000 people visit to this park every day. The wetland park has thus promoted recreational activity in the area, which can be regarded as a social benefit of the project, and which was calculated by using Equation (6):

$$
B_{S}=\sum_{t=1}^{n} \frac{d \times D}{(1+r)^{t}}
$$

where $B_{S}$ is the social benefit of increasing leisure area, $d$ is the unit recreation value, and $D$ is area of the wetland park. The unit recreation value of the wetland park was calculated through value convention, and was determined to be CNY $¥ 428,358 / \mathrm{km}^{2}(d)$. Globally, the average recreation value induced by the wetland park was estimated to be approximately CNY $¥ 470,680 / \mathrm{km}^{2}$ each year [27]. Recreation value is highly related to income, because consumers with a higher income spend more on recreation. According to the World Bank, the global Gross National Income (GNI) was US \$5494 per capita in 1997, whereas that of China was US $\$ 5000$ per capita in 2011. The ratio of China's income to average income worldwide is 0.9 , and thus China's average recreation value was determined to be CNY $¥ 428,358 / \mathrm{km}^{2}$.

\subsection{Total Cost and Benefit}

The total cost and total benefit of each project were determined by using Equations (7) and (8), respectively. These equations include all of the economic, environmental, and social cost, and the benefits values that were collected at the evaluation periods.

$$
C=C_{E}=I+\sum_{t=1}^{n} \frac{a \times M}{(1+r)^{t}}
$$




$$
B=B_{O 1}+B_{O 2}+B_{E 1}+B_{E 2}+B_{S}=\frac{\frac{w}{W} \times Y}{\beta}+\sum_{t=1}^{n} \frac{u \times U}{(1+r)^{t}} / 8+\sum_{t=1}^{n} \frac{G \times g}{(1+r)^{t}}+\sum_{t=1}^{n} \frac{O \times p_{1} \times p_{2}}{(1+r)^{t}}+\sum_{t=1}^{n} \frac{d \times D}{(1+r)^{t}}
$$

\subsection{Results and Discussion}

Reviewed altogether, the values of the eight water projects indicate the influence that the Sponge City Program has in Changde city. As Table 3 shows, the total initial investment for all of the projects is approximately CNY 312 million. The central government provides only $10 \%$ (CNY 30 million) of the initial investment. The remaining is currently and temporarily contributed by the local government, as $50 \%$ of the total investment is expected to be from the private sector. As the eight water projects do not lead to any environmental or social costs, the economic cost is the only cost that is considered in the analysis. Excluding project 1, all of the projects have similar initial investment and operation and management (O\&M) costs, because they have similar designs and scales of construction. Table 3 shows that project 1 has much higher initial investment than the other projects; this is because it was designed and planned by a German company while the other projects were designed by local companies.

Table 3. Economic analysis of water projects.

\begin{tabular}{cccccccccc}
\hline & & $\mathbf{1}$ & $\mathbf{2}$ & $\mathbf{3}$ & $\mathbf{4}$ & $\mathbf{5}$ & $\mathbf{6}$ & $\mathbf{7}$ & $\mathbf{8}$ \\
\hline \multirow{2}{*}{ Economic cost } & $\begin{array}{c}\text { Initial investment } \\
\text { (million Yuan) }\end{array}$ & 130 & 26 & 30 & 30 & 30 & 26 & 20 & 20 \\
\cline { 2 - 9 } & $\begin{array}{c}\text { O\&M cost } \\
\text { (million Yuan) }\end{array}$ & 9.7 & 8 & 9.7 & 9.7 & 9.7 & 8 & 8 & 8 \\
\hline Total cost & 139.7 & 34 & 39.7 & 39.7 & 39.7 & 34 & 28 & 28 \\
\hline $\begin{array}{c}\text { Economic } \\
\text { benefits }\end{array}$ & $\begin{array}{c}\text { Increase of Job } \\
\text { (million Yuan) }\end{array}$ & 3.3 & 2.75 & 3.3 & 3.3 & 3.3 & 2.75 & 2.75 & 2.75 \\
\cline { 2 - 9 } & $\begin{array}{c}\text { Tourism } \\
\text { (million Yuan) }\end{array}$ & 11.7 & 11.7 & 11.7 & 11.7 & 11.7 & 11.7 & 11.7 & 11.7 \\
\hline $\begin{array}{c}\text { Environmental } \\
\text { benefits }\end{array}$ & $\begin{array}{c}\text { Decrease of economic } \\
\text { loss due to flooding } \\
\text { (million Yuan) }\end{array}$ & 2.7 & 1.35 & 2.7 & 3.2 & 2.7 & 1.4 & 0.7 & 0.9 \\
\cline { 2 - 9 } & $\begin{array}{c}\text { Improvement on river } \\
\text { water quality } \\
\text { (million Yuan) }\end{array}$ & 64.5 & 16 & 64.5 & 48.3 & 24 & 12 & 120 & 52.34 \\
\hline Social benefits & $\begin{array}{c}\text { Increase of Leisure } \\
\text { (million Yuan) }\end{array}$ & 0.4 & 0.4 & 0.4 & 0.4 & 0.4 & 0.4 & 0.4 & 0.4 \\
\hline Total benefits & 82.6 & 32.2 & 82.6 & 67 & 42.1 & 28.2 & 135.6 & 68.1 \\
\hline Ratio of benefits to cost & 0.6 & 0.9 & 2 & 1.7 & 1.06 & 0.8 & 4.8 & 1.3 \\
\hline
\end{tabular}

Environmental benefit is the largest value provided by these projects and accounts for nearly $70 \%$ of total benefits. Flooding control and water quality improvement are the main objectives of the Sponge City Program. When compared with the benefit of flooding control, the benefit of water quality improvement is much higher and accounts for approximately $50 \%$ of the total benefits. Because of rapid economic development and urbanization, rivers and channels are severely polluted in many Chinese cities. This hampers urban development, degrades city residents' lives, and harms the city environment. Therefore, the improvement of water quality contributes to societal and economic development, and is the primary environmental benefit of the Sponge City Program.

Table 3 illustrates that five of the eight water projects are economically feasible because their ratios of benefits to cost are larger than 1 . This suggests that the water projects are largely economically feasible as they have high economic, social, and environmental benefits that outweigh the costs. From the public perspective, the Sponge City Program deserves to be promoted. 
Three of the eight water projects are economically infeasible: project 1 , project 2 , and project 6 . When comparing the costs and benefits of the eight projects, we find that project 1 has a larger initial investment, and project 2 and project 6 have relatively smaller environmental benefits from improving the water quality. These are likely the main reasons for their economic infeasibility. Project 1 was designed by a foreign company with high charges for service, leading to a higher initial cost, which contributes to project 1's economic infeasibility. Projects 2 and 6 are constructed in areas without severe water pollution; thus, the potential improvement in water quality is small. Although these projects still contribute to city flooding control, their benefits are not large enough to recover their costs, especially the initial investment cost. The economic infeasibility of these three projects can be attributed to either high initial investment spending or irrational project designs. A more integrated plan and intensive technological assessment are required before constructing water projects.

Many water projects are roughly, unscientifically, or irrationally planned for rapid construction, because water projects must be partially funded and constructed to obtain subsidies from the central government. The program incentivizes municipal governments' to accelerate the water projects. A city involved in the Sponge City Program is regarded as improving the urban water environment. This is a political benefit for municipal officials. Moreover, subsidies that are obtained from the central government for water project construction reduce the financial stress on municipal governments. Thus, parts of projects may be planned and constructed rashly, resulting in economically infeasibility.

\section{Financial Analysis}

\subsection{Financial Cost and Benefits}

From the perspective of project manager, financial cost means all expenses including initial investment and O\&M cost. Currently, eight water projects in Changde city are managed by a state-owned company that is regarded as the project manager. Currently there is not private finance involved into the projects yet, while $10 \%$ of initial investment is subsidized by the central government, which is defined as $S$. The determination of financial cost (defined as $F_{C}$ ) could be shown as Equation (9).

$$
F_{C}=(I-S)+\sum_{t=1}^{n} \frac{a \times M}{(1+r)^{t}}
$$

Temporarily, the profit of tourism of cruise in the Chuanzi River is the only income to the project manager, which could be regarded as the financial benefit $\left(F_{B}\right)$. It can be calculated through:

$$
F_{B}=B_{O 2}=\sum_{t=1}^{n} \frac{u \times U}{(1+r)^{t}} / 8
$$

\subsection{Results and Discussion}

Table 4 shows that none of the eight projects financial benefits exceed the financial cost. From the perspective of project managers, there is no incentive to invest and manage the project. The initial investment is much higher than the O\&M cost. If the initial investment were completely subsidized by the central government, then the private sector would be incentivized to manage the water projects. According to the financial analysis, the O\&M cost can be recovered through the financial benefit of tourism. But, it seems unrealistic to require the central government to provide all of the initial investment. An effective business model is therefore required to ensure that management funding that is capable of covering financial cost of a project is obtained. Financial infeasibility results in limited private funding into the program and water projects not being operational in the long term. 
Table 4. Financial analysis of water projects.

\begin{tabular}{cccccccccc}
\hline & $\mathbf{1}$ & $\mathbf{2}$ & $\mathbf{3}$ & $\mathbf{4}$ & $\mathbf{5}$ & $\mathbf{6}$ & $\mathbf{7}$ & $\mathbf{8}$ \\
\hline Financial cost & $\begin{array}{c}\text { Initial investment } \\
\text { (million Yuan) }\end{array}$ & 117 & 23.4 & 27 & 27 & 27 & 23.4 & 18 & 18 \\
\cline { 2 - 9 } & $\begin{array}{c}\text { O\&M cost } \\
\text { (million Yuan) }\end{array}$ & 9.7 & 8 & 9.7 & 9.7 & 9.7 & 8 & 8 & 8 \\
\hline Financial benefits & $\begin{array}{c}\text { Tourism } \\
\text { (million Yuan) }\end{array}$ & 11.7 & 11.7 & 11.7 & 11.7 & 11.7 & 11.7 & 11.7 & 11.7 \\
\hline Ratio of financial benefits to cost & 0.09 & 0.37 & 0.32 & 0.32 & 0.32 & 0.37 & 0.45 & 0.45 \\
\hline
\end{tabular}

Currently, municipal governments are primarily responsible for the construction and management. However, the municipal government has low concerns regarding the financial feasibility of the water projects. Cities with severe water pollution and flooding may be more interested in the program, because their economic and social development has been hindered by a poor water environment. Improvement of the water environment could bring social and political benefits to municipal governors. These types of cities actively implement the program and promote water project construction for social or political benefits, despite realizing that the projects may not be financially feasible. Cities without severe water problems may not have strong incentives to join the program, because these cities' development does not rely on water improvement. For example, Shenzhen, a demo city of the Sponge City Program, does not have a critical water problem. Shenzhen has built few water projects despite joining the Sponge City Program at the same time as Changde. Most sponge-city water projects are constructed because of political motivation. Whether the projects are economically and financially feasible is largely neglected by municipal governments.

\section{Conclusions}

The paper conducts economic and financial analysis of water projects of the Sponge City Program from the separate perspectives of government and project manager. From the government perspective, the economic analysis compares all of the potential economic, environmental, and social effects of water projects. From the perspective of the project manager, the financial analysis compares the revenues and costs of water projects. Changde city, a demo city in the Sponge City Program, is chosen for the analysis. Cost benefit analysis is performed to estimate the economic and financial feasibility of water projects. The results show that from the perspective of the government, the Sponge City Program should be promoted, as most water projects are economically feasible. From the perspective of the private sector, the program should not receive investment, because the revenue from the projects does not exceed the cost.

The water projects of the Sponge City Program provide many environmental benefits once operational, but they require substantial investment for construction. From the public's perspective, the Sponge City Program contributes positively to society. However, three of the eight projects in Changde city are not economically feasible, because these projects are not designed and planed rationally. From the perspective of the project manager, there is no incentive to build and manage these projects because the financial benefits cannot cover the financial costs. Without an effective business model or government-subsidized initial investment, it is a challenge to attract private capital into the Sponge City Program. Moreover, financial infeasibility could lead to the suspension of water projects in the future despite municipal government's management of the projects.

Most water projects in the Sponge City Program are built because of the political interests of the municipal government; the economic and financial feasibility of the projects are disregarded. The social and political incentives encourage municipal governments to construct water projects; but, the sustainable management and operation of water projects remain questionable. An effective 
policy is required to encourage the private sector to involve into the project management and become the main player in the program.

Acknowledgments: This research was funded by Social Science Foundation of Guangdong Province (grant No. GD15YGL03). I am grateful to the anonymous reviewers for their insightful comments.

Conflicts of Interest: The author declares no conflict of interest.

\section{References}

1. Yin, J.; Yang, D.; Yuan, Z.; Yuan, Y.; Wang, H.; Shi, X. Research on Historical and Future Spatial-temporal Variability of Precipitation in China. Adv. Meteorol. 2016, 2016, 9137201. [CrossRef]

2. Sang, Y.F.; Yang, M. Urban Waterlogs Control in China: More Effective Strategies and Actions are Needed. Nat. Hazards 2017, 85, 1291-1294. [CrossRef]

3. Yu, K.; Li, D.; Yuan, H.; Fu, W.; Qiao, Q.; Wang, S. “Sponge city": Theory and Practice. City Plan. Rev. 2015, 39, 26-36. (In Chinese)

4. Shi, R.; Xiao, Y.; Zhao, X. Research on the strategy in macroscopic theory of sponge city to microscopic sponge community construction. Ecol. Econ. 2016, 32, 223-227. (In Chinese)

5. $\mathrm{Xu}, \mathrm{J}$; Ren, T.; Wang, Y. Dilemma of sponge city construction and its countermeasures: Taking henan procivince as an example. Resour. Dev. Mark. 2016, 32, 550-555. (In Chinese)

6. Song, F.; Zhang, H. Problems and strategies in the construction and management of Chinese sponge city. Urban Dev. Stud. 2016, 23, 99-104. (In Chinese)

7. Sang, Y.F.; Yang, M. Urban waterlogs control in China: More effective strategies and actions are needed. Nat. Hazards 2016, 85, 1291-1294. [CrossRef]

8. Zhang, Y.; Li, J.; Wang, W. Discussion of sponge city construction in China. Water Wastewater Eng. 2016, 12, 7-11. (In Chinese)

9. Jiang, Y.; Zevenbergen, C.; Fu, D. Understanding the challenges for the governance of China's "sponge cities" initiative to sustainably manage urban stormwater and flooding. Nat. Hazards 2017, 89, 521-529. [CrossRef]

10. Liang, X.; Van Dijk, M.P. Evaluating the interests of different stakeholders in Beijing wastewater reuse systems for sustainable urban water management. Sustainability 2016, 8, 1098. [CrossRef]

11. Berg, S.; Marques, R. Quantitative studies of water and sanitation utilities: A benchmarking literature survey. Water Policy 2011, 13. [CrossRef]

12. The Telegraph News. Available online: http:/ /www.telegraph.co.uk/news/world/china-watch/business/ china-flooding-sponge-city/ (accessed on 26 June 2017).

13. Marques, R. Comparing private and public performance of Portuguese water services. Water Policy 2008, 10. [CrossRef]

14. Pinto, F.S.; Somoes, P.; Marques, R. Water services performance: Do operational environment and quality factors count? Urban Water J. 2017, 14, 773-781. [CrossRef]

15. Zeng, W.; Song, Q.; Chen, R. Ecological and environmental water requirements of urban river course: Taking Chuanzihe River as an example. Ecol. Environ. 2004, 13, 528-531. (In Chinese)

16. Yang, C.; Xiao, L.; Shen, J. Analysis and assessment of water environment quality in changde section of Yuanshui River. J. Heibei Agric. Sci. 2011, 15, 110-111. (In Chinese)

17. Chen, Z. The history of flood and fire disasters in Changde city. Wu Ling Xue Kan 1998, 4, 90-93. (In Chinese)

18. Liang, X. The Economics of Sustainable Urban Water Management: The Case of Beijing. Ph.D. Thesis, Erasmus University Rotterdam, Rotterdam, The Netherlands, Octorber 2011.

19. Rawski, T.G. Economic growth and employment in China. World Dev. 1979, 7, 767-782. [CrossRef]

20. Li, H. A study on the relation between economic growth and employment elasticity. J. Financ. Econ. 2003, 29, 24-27. (In Chinese)

21. Zhang, H.; Xu, X.; Zhang, L.; Wang, H. The evaluation of flood in china during 2000-2010. J. Econ. Water Res. 2011, 29, 5-10. (In Chinese)

22. Dai, S.; Cao, K. Countermeasure of urban flood and drainage in China. Mod. Urban Res. 2012, 1, 21-28. (In Chinese)

23. Feng, P.; Cui, G.; Zhong, Y. On the evaluation and prediction of urban flood economic loss. J. Hydraul. Eng. 2001, 8, 64-72. (In Chinese) 
24. Liu, C.; Liu, G.; Qiu, L. Assessment and application of urban flood disaster losses. J. Econ. Water Res. 2009, 27, 36-39.

25. Shi, R.; Liu, N.; Li, L.; Ye, L.; Liu, X.; Guo, G. Application of rainstorm and flood inundation model in flood disaster economic loss evaluation. Torrential Rain Disasters 2013, 32, 379-384. (In Chinese)

26. Li, J.; Liao, W.; Chen, M.; Wang, H. Calculation of economic loss caused by water pollution in China. China Water Res. 2003, 21, 63-66.

27. Costanza, R.; D’Arge, R.; De Groot, R.; Farber, S.; Grasso, M.; Hannon, B.; Limburg, K.; Naeem, S.; O'Neill, R.V.; Paruelo, J.; et al. The value of the world's ecosystem services and natural capital. Nature 1997, 387, 253-260. [CrossRef] 